\title{
Inequality, residential segregation by income, and mortality in US cities
}

\section{P Lobmayer, R G Wilkinson}

See end of article for authors' affiliations ......................

Correspondence to: Professor R G Wilkinson, Division of Public Health Sciences, University of Nottingham Medical School, Nottingham NG7 2UH, UK; Richard.Wilkinson@ Nottingham.ac.uk

Accepted for publication 25 May 2001

\begin{abstract}
Study objective: This study was designed to discover whether the relation between income inequality and population death rates within the United States was mediated by the degree of residential segregation between rich and poor.

Design: Using data for 276 metropolitan areas in the USA, residential segregation was defined as the extent to which people with different levels of income live in the same or different census tracts. Two segregation measures were used: the ratio of income inequality between household within tracts to the inequality in average income between tracts, and the Jargowsky Neighbourhood Sorting Index.

Main results: Results suggest that segregation within urban areas is associated with an additional mortality burden. However, the association between income inequality and mortality in these metropolitan statistical areas was found to be independent of the degree of economic segregation between their constituent neighbourhoods.

Conclusions: Most of the association between income inequality and mortality is not mediated by the effects of greater residential segregation.
\end{abstract}

A lthough numerous papers suggest that mortality rates tend to be higher where income differences are larger, ${ }^{1-3}$ there is little agreement as to why this is so. The best evidence suggests that a tendency for more unequal areas to have a larger proportion of poor people is not an adequate explanation. ${ }^{4}$ Other suggested explanations have emphasised the inadequacies of the material infrastructure in poorer areas ${ }^{5}$ and the effects of more divisive social relations in less egalitarian places. ${ }^{67}$

Whether rich and poor live in the same or in different neighbourhoods might also be expected to have a major influence on the effects of inequality. Analysing data from the 30 largest metropolitan areas in the United States, Waitzman and Smith ${ }^{8}$ reported that, after taking account of the effects of individual incomes, greater economic segregation is associated with higher mortality rates, specially among the poor. As they point out, "These results suggest that economic segregation in metropolitan areas might be a factor in the association ...between ...socioeconomic inequalities and mortality" (page 370).

Rather than looking merely at the health effects of economic segregation in itself, we were primarily interested in the question of whether economic segregation might mediate the effects of income inequality. We therefore decided to see if the relation between income inequality and mortality was dependent on the effects of residential segregation by income. Mortality has been found to be related to income inequality at both the State and Metropolitan Statistical Area (MSA) levels in the United States. ${ }^{29}$ As the concept of residential segregation is normally applied only to urban areas and its meaning is less clear in rural areas, we decided to examine the ecological effects of residential segregation within the MSAs. The inclusion of income data in the US Census makes it possible to examine the extent of segregation by income between small areas within each metropolitan area.

\section{METHODS}

Mortality and population data were downloaded from the US Center for Disease Control's "Wonder" web site. ${ }^{10}$ We used population data for 1990 and combined mortality for the three years 1989,1990 , and 1991 to give more stable mortality rates. The following six age standardised mortality rates were calculated for each sex separately: infant mortality, mortality 1-14 years, 15-34 years, 35-64 years, 65 years and over, and for all ages combined. As a measure of all premature mortality we also used potential years of life lost (PYLL) below age 65. ${ }^{11}$ Male and female PYLL and the all ages mortality rates were standardised on the population of the whole United States in 1990. Our analysis covered 276 MSAs: official definitions identified 281 MSAs in 1999 but CDC mortality data were unavailable for five in Alaska and Puerto Rico.

Household income data were downloaded from the US Census Bureau web site. ${ }^{12}$ Income recorded in the census is total income (before taxation) from all sources, including social security. We used income data from the 1990 US census for each of the 45563 populated census tracts situated within the 276 MSAs (that is, about three quarters of all tracts in the USA). The populations of these tracts ranged from 2 to 71 872, with a mean of 4346. In taking census tracts as approximations of neighbourhoods we were following the precedent set by other studies of residential segregation. ${ }^{813}{ }^{14}$ MSA populations ranged from 57000 in 22627 households in Enid, Oklahoma, to 18087000 in 6617074 households in New York.

Income inequality was calculated for each MSA and for each tract within an MSA. Taking each MSA as a whole, we first calculated the overall inequality of all household incomes in that MSA. Second, for each tract we calculated the within tract income inequality (WTI). The WTI measures were then grouped into the MSAs to which they belonged, and we calculated an average WTI for each MSA. Finally, we took the mean incomes of each tract and calculated the average between tract inequality (BTI) for each MSA. BTI was calculated for each MSA as the variance of the logarithm of mean tract income regardless of the proximity of tracts within each area. In calculating the average WTI and BTI, each tract was weighted

Abbreviations: PYLL, potential years of life lost; MSA, Metropolitan Statistical Area; WTI, within tract income inequality; BTI, between tract inequality; Jl, Jangowsky Index 
Table 1 Means and standard deviations (SD) of variables

\begin{tabular}{lll}
\hline Variables & Mean & SD \\
\hline Overall inequality (log income variance) & 0.14 & 0.014 \\
Within tracts inequality (log income variance) & 0.12 & 0.010 \\
Between tracts inequality (log income variance) & 0.020 & 0.008 \\
Betweentract/within tract inequality ratio & 0.17 & 0.07 \\
Jargowsky segregation index & 0.34 & 0.07 \\
Mean household income & 34481 & 5169 \\
Household size & 2.70 & 0.20 \\
Male infant mortality * & 1035 & 230 \\
Male mortality rate 1-14 years* & 36.7 & 9.12 \\
Male mortality rate 15-34 years* & 159.9 & 43.6 \\
Male mortality rate 35-64 years* & 683.0 & 122.1 \\
Male mortality rate 65 and over* & 5826.8 & 611.1 \\
Male mortality rate all ages* & 914.6 & 104.5 \\
Male potential years of life lost < age 65 & 69.3 & 13.3 \\
Female infant mortality rate* & 804 & 190 \\
Female mortality rate 1-14 years* & 26.4 & 8.0 \\
Female mortality rate 15-34 years* & 60.4 & 15.7 \\
Female mortality rate 35-64 years* & 384.7 & 59.6 \\
Female mortality rate 65 and over* & 4395.0 & 360.8 \\
Female mortality rate all ages* & 812.4 & 72.8 \\
Female potential years of life lost < age 65 & 37.5 & 6.6 \\
\hline *Death rates are per 100000. & & \\
\hline
\end{tabular}

according to its population. Thus, for each MSA, we had the overall income inequality, the average WTI, and the BTI. At each of these levels, inequality was measured by the variance of logarithm of household income. We chose this inequality measure because it enables a mathematically exact division of the total inequality in each MSA into within tract and between tract components. Summing the within tract and between tract variance of log incomes in any state or MSA gives the variance of log income in the whole MSA. (We are grateful to Angus Deaton for advice on this point).

Our first measure of residential segregation by income in each MSA was the ratio of BTI to WTI inequality (BTI/WTI). Given some level of inequality in an MSA as a whole, if there is less inequality within its tracts, there must be more between them. Higher values of this ratio therefore indicate greater segregation: rich and poor are less likely to live in the same tracts.

For comparison we also used the Jargowsky's Neighbourhood Sorting Index. ${ }^{13}$ The formula for the Jargowsky Index (JI) is the standard deviation of the mean incomes of neighbourhoods (in this case tracts) divided by the standard deviation of individual household income in the whole MSA. To correspond with the denominator, each tract's mean income was weighted in the calculation of the numerator, by the number of households it contained. The JI is then the ratio of inequality between tracts to the total inequality, where inequality is measured by the standard deviation of household income. It is mathematically (but not necessarily empirically) independent of the mean level of income and the magnitude of overall inequality in the area. Higher values indicate more segregation between rich and poor. Our two measures of segregation were then measures of average segregation by tract within each MSA.

The statistical analysis used multiple regression. To see whether the amount of residential segregation by income affected the relation between mortality and overall MSA income inequality, we regressed the mortality rates on overall inequality and our two measures of residential segregation. We included mean household income and mean household size as covariates in all models. As populations in some of the MSAs were as low as 60000 , analyses were weighted by number of persons living in each.

\section{RESULTS}

Table 1 shows the means and standard deviations of all dependent and independent variables. Among the MSAs the correlation between overall inequality and its within tract and between tract components was high $(r=0.9$ and $r=0.8$ respectively). However, when these two components were combined to produce our BTI/WTI measure of segregation, the collinearity with overall inequality was reduced to an acceptable level: BTI/WTI ratio and the JI showed correlations with overall inequality of 0.60 and 0.65 respectively. The correlation between our two measures of segregation BTI/WTI was so

Table 2 Results of regressions using inequality and segregation in separate models: (i) The relation between income inequality and death rates, and (ii) The relation between segregation and death rates

\begin{tabular}{|c|c|c|c|c|c|c|}
\hline \multirow[b]{2}{*}{ Death rates } & \multicolumn{3}{|c|}{${ }^{*}$ Regression i Income inequality } & \multicolumn{3}{|c|}{ *Regression ii Segregation (BTI/WTI) } \\
\hline & $\beta$ & $\mathrm{p}$ & Adj $r^{2}$ & $\beta$ & $\mathrm{p}$ & Adj $r^{2}$ \\
\hline \multicolumn{7}{|l|}{ Under 1 year } \\
\hline $\mathrm{m}$ & 0.43 & 0.000 & 0.14 & 0.62 & 0.000 & 0.29 \\
\hline f & 0.48 & 0.000 & 0.16 & 0.65 & 0.000 & 0.29 \\
\hline \multicolumn{7}{|l|}{$1-14$ years } \\
\hline $\mathrm{m}$ & 0.26 & 0.000 & 0.17 & 0.15 & 0.028 & 0.14 \\
\hline f & 0.29 & 0.000 & 0.14 & 0.23 & 0.001 & 0.12 \\
\hline \multicolumn{7}{|l|}{$15-34$ years } \\
\hline $\mathrm{m}$ & 0.63 & 0.000 & 0.38 & 0.40 & 0.000 & 0.17 \\
\hline f & 0.72 & 0.000 & 0.37 & 0.32 & 0.000 & 0.07 \\
\hline \multicolumn{7}{|l|}{$35-64$ years } \\
\hline $\mathrm{m}$ & 0.82 & 0.000 & 0.48 & 0.45 & 0.000 & 0.14 \\
\hline $\mathrm{f}$ & 0.68 & 0.000 & 0.32 & 0.59 & 0.000 & 0.24 \\
\hline \multicolumn{7}{|c|}{ Over 65 years } \\
\hline $\mathrm{m}$ & 0.26 & 0.000 & 0.12 & 0.48 & 0.000 & 0.24 \\
\hline $\mathrm{f}$ & 0.30 & 0.000 & 0.08 & 0.52 & 0.000 & 0.20 \\
\hline \multicolumn{7}{|l|}{ All ages } \\
\hline $\mathrm{m}$ & 0.62 & 0.000 & 0.28 & 0.58 & 0.000 & 0.24 \\
\hline & 0.47 & 0.000 & 0.16 & 0.59 & 0.000 & 0.25 \\
\hline \multicolumn{7}{|l|}{ PYLL } \\
\hline $\mathrm{m}$ & 0.78 & 0.000 & 0.47 & 0.48 & 0.000 & 0.19 \\
\hline$f$ & 0.72 & 0.000 & 0.37 & 0.56 & 0.000 & 0.21 \\
\hline
\end{tabular}




\begin{tabular}{|c|c|c|c|c|c|}
\hline \multirow[b]{3}{*}{ Death rates } & \multicolumn{5}{|c|}{ *Regression results } \\
\hline & \multicolumn{2}{|c|}{ Overall inequality } & \multicolumn{2}{|c|}{$\begin{array}{l}\text { Segregation } \\
\text { (BTI/WTI) }\end{array}$} & \multirow[b]{2}{*}{ Adj $r^{2}$} \\
\hline & $\beta$ & $P$ & $\beta$ & $\mathrm{p}$ & \\
\hline \multicolumn{6}{|l|}{ Under 1 year } \\
\hline $\mathrm{m}$ & 0.19 & 0.004 & 0.54 & 0.001 & 0.31 \\
\hline & 0.24 & 0.000 & 0.55 & 0.001 & 0.32 \\
\hline \multicolumn{6}{|l|}{$1-14$ years } \\
\hline $\mathrm{m}$ & 0.24 & 0.001 & 0.04 & 0.573 & 0.17 \\
\hline$f$ & 0.24 & 0.001 & 0.12 & 0.106 & 0.15 \\
\hline \multicolumn{6}{|l|}{$15-34$ years } \\
\hline $\mathrm{m}$ & 0.62 & 0.000 & 0.13 & 0.047 & 0.39 \\
\hline f & 0.72 & 0.000 & 0.01 & 0.930 & 0.37 \\
\hline \multicolumn{6}{|l|}{$35-64$ years } \\
\hline $\mathrm{m}$ & 0.78 & 0.000 & 0.11 & 0.064 & 0.49 \\
\hline$f$ & 0.53 & 0.000 & 0.36 & 0.001 & 0.40 \\
\hline \multicolumn{6}{|c|}{ Over 65 years } \\
\hline $\mathrm{m}$ & 0.06 & 0.363 & 0.45 & 0.001 & 0.24 \\
\hline f & 0.09 & 0.202 & 0.48 & 0.001 & 0.20 \\
\hline \multicolumn{6}{|l|}{ All ages } \\
\hline $\mathrm{m}$ & 0.46 & 0.000 & 0.37 & 0.001 & 0.36 \\
\hline$f$ & 0.27 & 0.000 & 0.47 & 0.001 & 0.29 \\
\hline \multicolumn{6}{|l|}{ PYLL under 65} \\
\hline $\mathrm{m}$ & 0.71 & 0.000 & 0.17 & 0.004 & 0.48 \\
\hline$f$ & 0.60 & 0.000 & 0.29 & 0.001 & 0.42 \\
\hline
\end{tabular}

*The model includes mean household income and mean household size covariates and is weighted by MSA populations.

high $(r=0.91)$ that relations with mortality were essentially the same throughout the analysis and for this reason we show only the results using BTI/WTI.

We looked first at how mortality was related separately to income inequality and then to residential segregation. Table 2 shows results of two different models: the first with income inequality but not segregation, and the second with segregation but not inequality. Both models included mean household income and household size and MSAs were weighted by their populations. The results of the first model confirm the strong associations previously reported ${ }^{29}$ between income inequality and mortality at the MSA level. PYLL and all ages mortality rates for both men and women separately was strongly and highly significantly related to the variance of log income (in all cases $\mathrm{p}<0.001$ ) (see table 2 ).

When the income inequality variable was replaced by our measures of residential segregation (model ii. in table 2) the regressions showed that segregation was positively and significantly related to all the age specific mortality rates, including PYLL and all ages mortality rates, for men and women (in almost all cases $\mathrm{p}<0.001$ ). Metropolitan areas in which rich and poor tend to live in separate areas tend to have higher mortality rates.

To discover how the association between mortality and income inequality might be affected by the degree of residen-

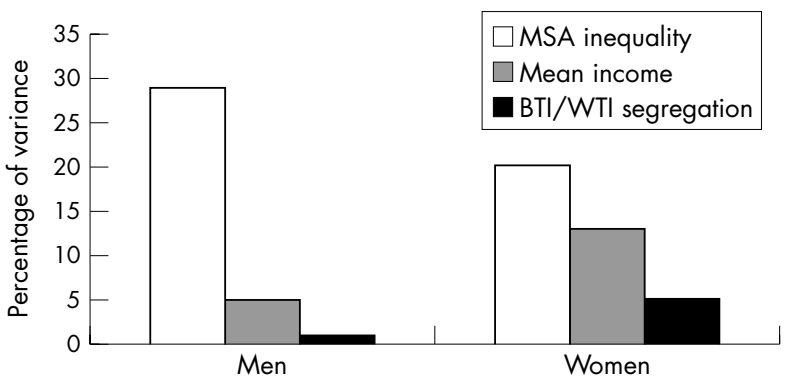

Figure 1 Percentage of variance in PYLL under 65 years of age explained by each variable independently of the other two. tial segregation, we put overall income inequality and measures of residential segregation into the model at once (including mean household income and mean household size as before). The results of these regressions using the BTI/WTI segregation measure are shown in table 3. PYLL and the all ages mortality rates for both men and women remain significantly and independently related to income inequality. Among the age specific death rates only the relations among men and women over 65 years does not show significant independent relations with income inequality.

The associations between mortality rates and residential segregation, independent of MSA income inequality, are also shown in table 3. Segregation was independently and positively related to infant mortality and to mortality over 65 years in both sexes, and to death rates for women 35-64 years. The relation between segregation and mortality among men 15-34 years old just reached statistical significance and with men 35-64 years it just failed to reach significance. In short, segregation, independent of inequality, was more closely related to mortality at each end of life than to mortality among children and younger adults. These age specific associations were however enough to produce significant associations with the all ages mortality rates and with PYLL for both sexes.

PYLL and all ages mortality rates for both sexes were then independently and significantly related to both inequality and segregation.

Using the JI instead of BTI/WTI measure of segregation to repeat the analysis shown in table 3 showed no important differences between the two sets of results. MSA inequality continued to be independently related to all the death rates except those for men and women over 65 years-though the association for women over 65 years bordered on statistical significance $(p=0.06)$. The JI was again independently related to death rates at each end of life though, among men, it was only mortality in childhood which was not independently related to segregation.

\section{DISCUSSION}

Income inequality seems to be related to mortality independently of the measures of economic segregation, and the segregation measures were related-independently of overall inequality-to some of the age specific mortality rates, to PYLL and to the all ages mortality rates. The sizes of the statistically independent effects on male and female PYLL of overall inequality, segregation, and mean income in MSAs is shown in figure 1. Controlling for segregation attenuates the effect of income inequality on infant mortality and removes the effect on men and women over 65 years. However, after controlling for residential segregation, mean income and household size, substantial and significant relations remain between income inequality and all the other death rates.

It might be expected that the degree of segregation between income groups would be driven by the extent of overall income inequality. Not only has residential segregation by income increased in the USA as income differences have widened, ${ }^{13}$ but in this cross sectional analysis, both measures of segregation are strongly correlated with overall income inequality $(r=0.6)$. One effect of this is that, although we can establish that they have independent effects, the apportionment of that part of the mortality variance that is related to the covariance between inequality and segregation is unreliable. Segregation may be statistically related to mortality only because it is closely associated with inequality.

In the hope of casting more light on these relations we ran more multiple regressions, replacing overall inequality and our segregation measures with WTI and BTI as two separate variables. As before, the model included mean income and mean household size. The results are shown in table 4. If segregation rather than inequality was regarded as the primary variable, it might have been expected that within tract 


\section{Key points}

- The degree of residential segregation by income is closely related to the extent of income inequality in US cities.

- Age specific mortality rates throughout life are associated with both income inequality and residential segregation by income.

- Infant mortality and mortality after age 65 are more strongly associated with segregation than income inequality.

- After controlling for segregation, mortality at other ages, and potential years of life lost before age 65 remain strongly associated with income inequality.

\begin{tabular}{|c|c|c|c|c|c|}
\hline \multirow[b]{3}{*}{ Death rates } & \multicolumn{5}{|c|}{${ }^{*}$ Regression results } \\
\hline & \multicolumn{2}{|c|}{$\begin{array}{l}\text { Within tract } \\
\text { inequality }\end{array}$} & \multicolumn{2}{|c|}{$\begin{array}{l}\text { Between tract } \\
\text { inequality }\end{array}$} & \multirow[b]{2}{*}{$r^{2}$} \\
\hline & $\beta$ & $p$ & $\beta$ & $\mathrm{p}$ & \\
\hline \multicolumn{6}{|l|}{ Under 1 year } \\
\hline $\mathrm{m}$ & -0.04 & 0.420 & 0.70 & 0.001 & 0.31 \\
\hline$f$ & -0.02 & 0.750 & 0.73 & 0.001 & 0.33 \\
\hline \multicolumn{6}{|l|}{$1-14$ years } \\
\hline $\mathrm{m}$ & 0.15 & 0.016 & 0.18 & 0.016 & 0.17 \\
\hline$f$ & 0.12 & 0.061 & 0.27 & 0.000 & 0.15 \\
\hline \multicolumn{6}{|l|}{$15-34$ years } \\
\hline $\mathrm{m}$ & 0.36 & 0.000 & 0.48 & 0.000 & 0.39 \\
\hline$f$ & 0.45 & 0.000 & 0.42 & 0.000 & 0.37 \\
\hline \multicolumn{6}{|l|}{$35-64$ years } \\
\hline m & 0.47 & 0.000 & 0.55 & 0.000 & 0.49 \\
\hline$f$ & 0.23 & 0.000 & 0.68 & 0.000 & 0.40 \\
\hline \multicolumn{6}{|l|}{ Over 65 years } \\
\hline $\mathrm{m}$ & -0.09 & 0.120 & 0.52 & 0.000 & 0.23 \\
\hline$f$ & -0.08 & 0.155 & 0.57 & 0.000 & 0.20 \\
\hline \multicolumn{6}{|l|}{ All ages } \\
\hline $\mathrm{m}$ & 0.19 & 0.000 & 0.66 & 0.000 & 0.36 \\
\hline & 0.03 & 0.600 & 0.66 & 0.000 & 0.29 \\
\hline \multicolumn{6}{|l|}{ PYLL under 65} \\
\hline $\mathrm{m}$ & 0.40 & 0.000 & 0.58 & 0.000 & 0.49 \\
\hline f & 0.29 & 0.000 & 0.66 & 0.000 & 0.42 \\
\hline
\end{tabular}

* The model includes mean household income and mean household size covariates and is weighted by MSA populations.

inequality (less segregation) would be negatively related to mortality. However, both between tract and within tract inequality are strongly related to many of the mortality rates and all the statistically significant relations are positive. This suggest that inequality is damaging whether it is within or between tracts, and that any effect of segregation is of secondary importance.

What light do these results cast on the nature of the relation between income inequality and mortality? One way in which inequality might be thought to influence mortality is through the health effects of the inadequate infrastructure, schools, and other services in poorer areas consequent on their reduced local tax base and political influence. Such an affect should be largely captured by the extent of residential segregation that tends to accompany greater income inequality. While our results show an independent association between residential segregation and mortality that is consistent with such an effect, it does not account for most of the association between inequality and mortality. We had originally included in this study an analysis of residential segregation by income in the 50 states as well as within the MSAs. We left it out of this report partly because it was not clear what the concept of residential segregation would mean in rural areas (where everyone might be regarded as spatially segregated from everyone else) and partly at the suggestion of referees. The only substantial difference between the results for the State and MSA level analyses was that at the State level residential segregation between census tracts had no significant effects on mortality which were independent of State income inequality, on any of the mortality rates. Although both State inequality and residential segregation within states were related to mortality on their own, when both were entered into the regression together, only State inequality had statistically significant independent effects on mortality. This is worth pointing out because, despite the difficulty in interpreting the meaning of segregation in non-urban areas, rural areas with concentrated poverty would still tend to suffer from less good services and infrastructure. Therefore the fact that residential segregation did not seem to contribute to the association between State income inequality and mortality suggests that poorer local services may have only a minor influence on mortality.

There is however some evidence that there may be important exceptions to this last point. Table 2, in which mortality was regressed separately on inequality and segregation, suggests a tendency for associations with segregation to be strongest in the age groups where the relation with inequality is weaker. In both sexes, infant mortality rates and mortality over 65 , are the only age specific mortality rates related more closely to segregation than to inequality. The same pattern recurs in table 3 , in which inequality and segregation are entered into the same equation to show their effects independently of each other. In the MSAs, mortality at each end of life is related more closely to segregation than to inequality.

It is, however, among the old and the very young that we might expect the impact of medical care to be greatest. Indeed, a paper by Shi $e t$ al $^{15}$ suggested that the relation between State income inequality and mortality was partly attributable to fewer primary care physicians per head of population in the less egalitarian states. That paper reported that the provision of primary care physicians was related most strongly to postneonatal and stroke mortality-which is of course most common in later life. If mortality at each end of life is influenced by access to primary care, and access is-as the inverse care law ${ }^{16}$ suggests-worse in the poorer areas, then segregation may increase mortality by reducing access to primary care. However, whether the impact of medical care is strong enough to compete with the influence of social factors as a major determinant of infant mortality remains controversial and many of the social risk factors are likely to be increased by the residential segregation of the poor in the inner cities. ${ }^{17} 18$

But although there is evidence that lends itself to such interpretations among infants and the elderly, our data suggest that rather than explaining the effect of inequality, any such effect is statistically rather separate from the impact of inequality. Mortality among children and people of working age seems much more closely related to inequality than to segregation. We suspect that the main effects of inequality in these age groups are more likely to derive from aspects of the experience of relative deprivation and low social status that are not dependent on the degree of residential segregation by income.

In conclusion, though residential segregation of rich and poor is associated with higher mortality rates, both before and after controlling for income inequality in US metropolitan areas, it does not account for most of the association between mortality and the overall income inequality in those areas.

\section{ACKNOWLEDGEMENTS}

The authors were supported by a grant from MRC. They are grateful to Dr Mah-j Soobader and Dr Bruce Kennedy for advice on methods and helpful comments on an earlier draft of this paper.

Authors' affiliations

P Lobmayer, Institute of Public Health, Semmelweis University of Medicine, Budapest, Hungary 
R G Wilkinson, Division of Public Health Sciences, University of Nottingham Medical School and International Centre for Health and Society, University College London, UK

\section{REFERENCES}

1 Kawachi I, Kennedy B, Wilkinson RG. eds. Income inequality and health. The Society and Population Health Reader. Vol 1. New York: New Press, 1999

2 Lynch J, Kaplan GA, Pamuk ER, et al. Income inequality and mortality in metropolitan areas of the United States. Am J Public Health 1998;88:1074-80.

3 Hales S, Howden-Chapman P, Salmond C, et al. National infant mortality rates in relation to gross national product and distribution of income. Lancet 1999;354:2047.

4 Wolfson M, Kaplan G, Lynch J, et al. The Relationship Between Income Inequality and Mortality: an empirical demonstration. BM 1999;319:953-7.

5 Muntaner C, Lynch J. Income inequality, social cohesion and class relations: A critique of Wilkinson's neo-Durkheimian research program. Int J Health Serv 1999:29:59-81.

6 Wilkinson RG. Inequality and the social environment: a reply to Lynch et al. J Epidemiol Community Health 2000;54:411-13.

7 Marmot M, Wilkinson RG. Income and health: psychosocial and material pathways: a reply to Lynch et al. BM 2001;322:1233-6.
8 Waitzman NJ, Smith KR. Separate but lethal: the effects of economic segregation on mortality in metropolitan America. Milbank Memorial Fund Q 1998;76:341-73

9 Kennedy BP, Kawachi I, Prothrow-Stith D. Income distribution and mortality: cross sectional ecological study of the Robin Hood index in the United States. BM 1996:312:1004-7.

10 Center for Disease Control. http://wonder.cdc.gov/mortsql.shtml

11 Blane D, Davey Smith G, Bartley M. Social class differences in years of potential life lost: size, trends, and principal causes. BM 1990;301:429-32.

12 US Census Bureau. http://www.census.gov/population/estimates/ metro-city/a99mfips.txt

13 Jargowsky P. Take the money and run: economic segregation in U.S. metropolitan areas. American Sociological Review 1996;61:984-98.

14 White MJ. American neighborhoods and residential differentiation. New York: Russel Sage Foundation (Census Monograph Series), 1987.

15 Shi L, Starfield B, Kennedy B, et al. Income inequality, primary care, and health indicators. J Fam Pract 1999;48:275-84.

16 Hart JT. The inverse care law. Lancet 1971;i:405-12.

17 Sable MR, Wilkinson DS. Impact of perceived stress, major life events and pregnancy attitudes on low birth weight. Fam Plann Perspect 2000;32:288-94.

18 Olson GL, Saade GR, Nagey DA. Active recruitment into health care and its effect on birth weight and gestational age at delivery. J Matern Fetal Investigation 1997; 7:122-5. 